\title{
Methanol Poisoning: Factors Associated with Neurologic Complications
}

\author{
Todd J. Anderson, Ashfaq Shuaib and Werner J. Becker
}

\begin{abstract}
Hospital records of thirty patients with methanol poisoning were studied. Neurologic manifestations at presentation including coma, seizures and decreased visual acuity were seen in nineteen patients. The mean blood $\mathrm{pH}$ at presentation was significantly lower in the patients with these neurologic signs and symptoms than in the eleven patients without them $(\mathrm{p}<0.05)$. Methanol levels at presentation tended to be higher in patients with neurologic manifestations at presentation and these patients tended to present later after methanol ingestion than those patients without neurologic manifestations. Fifteen patients with methanol poisoning developed serious neurologic sequelae or died. The mean blood $\mathrm{pH}$ was significantly lower in this patient group than in those who survived without neurologic sequelae $(p<0.05)$. Methanol levels at presentation were not different in the patients who developed neurologic sequelae or died as compared to those who did not. The time from ingestion of methanol to presentation at the hospital was however significantly longer in those patients who developed neurologic sequelae or died $(p<0.05)$. Initiation of treatment within eight hours of ingestion of methanol was associated with a better clinical outcome.
\end{abstract}

RÉSUMÉ: Empoisonnement au méthanol: facteurs associés aux complications neurologiques Nous avons étudié les cas de trente patients ayant subi un empoisonnement au méthanol. Dix-neuf patients présentaient des manifestations neurologiques à la consultation initiale, incluant le coma, les convulsions et une diminution de l'acuité visuelle. Le pH sanguin moyen au moment de la consultation initiale était significativement plus bas chez les patients qui présentaient ces signes et ces symptômes neurologiques que chez les onze patients chez qui ils étaient absents $(p<0.05$ ). Les taux de méthanol au moment de la consultation initiale avaient tendance à être plus hauts chez les patients qui présentaient des manifestations neurologiques au moment de la consultation et ces patients en général avaient consulté plus tardivement après l'ingestion de méthanol que les patients qui ne présentaient pas de manifestation neurologique.

Quinze patients ayant subi un empoisonnement au méthanol ont développé des séquelles neurologiques sérieuses ou sont décédés. Le pH sanguin moyen était significativement plus bas dans ce groupe de patients comparé à celui des patients qui ont survécu sans séquelle neurologique $(p<0.05)$. Les niveaux de méthanol au moment de la consultation n'étaient pas différents chez les patients qui ont développé des séquelles neurologiques ou qui sont décédés comparativement à ceux qui s'en sont tirés indemnes. Cependant, le laps de temps écoulé entre l'ingestion de méthanol et la moment de la consultation à l'hôpital était significativement plus long chez les patients qui ont développé des séquelles neurologiques ou qui sont décédés $(\mathrm{p}<0.05)$. L'institution du traitement en dedans de huit heures de l'ingestion du méthanol était associée à une meilleure évolution clinique.

Can. J. Neurol.Sci. 1989; 16:432-435

Methanol ingestion can result in serious toxicity, and many cases have been reported in the medical literature. ${ }^{1-6}$ The ingested methanol is converted to formic acid, the toxic metabolite responsible for many of the clinical manifestations and also for the high anion gap metabolic acidosis that accompanies methanol toxicity.7-11 Symptoms resulting from methanol poisoning include visual disturbances ranging from blurred vision to blindness, altered consciousness, nausea, vomiting, abdominal pain, headache and dyspnea.! The physical signs of methanol poisoning are not specific, but include non-reactive pupils, retinal edema, hyperaemia of the optic disc, disorientation, decreased level of consciousness and abdominal tenderness. 1,4
Standard treatment consists of intravenous bicarbonate for the acidosis, administration of ethanol to inhibit conversion of methanol to formate, and hemodialysis to remove methanol and formate. ${ }^{12-15}$ Recovery from methanol poisoning is often complete, but serious complications including ocular toxicity and neurologic sequelae can occur. 16-28

There is little information available in the literature to explain why some patients present with neurologic symptoms and signs, and why some patients but not others go on to develop major neurologic sequelae. To answer these questions, we have reviewed our experience with methanol poisoning over the last ten years with regard to the neurologic manifestations of methanol ingestion.

From the Departments of Internal Medicine, and Clinical Neurosciences, University of Calgary, Calgary

Received June 7, 1988. Accepted in final form June 19, 1989

Reprint requests to: Dr. Werner J. Becker, Calgary General Hospital, M4-022, 841 Centre Ave. E., Calgary, Alberta, Canada T2E 0A1 


\section{METHODS}

Hospital charts of patients admitted with a diagnosis of methanol poisoning over the past ten years to hospitals affiliated with the University of Calgary were reviewed retrospectively. Patients were included in the study if an anion gap of greater than 20 was present with no underlying cause other than methanol ingestion, and if methanol was detected in the serum. Using these criteria, 30 patients were admitted to the study. Patients were treated in an intensive care unit with intravenous bicarbonate, intravenous ethanol and hemodialysis until methanol was no longer detectable in the serum. Treatment was always begun within one hour of presentation.

We reviewed the patient records for neurologic manifestations at clinical presentation and for evidence of long term neurologic sequelae. Patients were considered to have neurologic signs and symptoms at presentation if they had seizures, coma, or decreased visual acuity (20/100 or worse) on admission. 6 Visual acuity had been measured in all patients who complained of visual symptoms. Neurologic sequelae were considered to be present if patients showed a persistent reduction in visual acuity to less than $20 / 100,17,19$ or showed persistent major abnormalities in the neurologic examination. ${ }^{24}$ Patient follow-up was limited to the length of their hospital stay for most patients. Followup for patients with reduced visual acuity was 4 to 30 days, and for the patients with more major neurological sequelae ranged from several months to over one year. Final patient outcome with regard to survival or death was also recorded. Although the immediate cause of death is not always known in patients dying of methanol toxicity, many groups have demonstrated at autopsy sufficient damage to the brain to account for death. 1,9,18,25 Patients who survived without neurologic sequelae recovered completely.

Student's T test (unpaired) was used to compare the groups in Tables 2 and 3. The values expressed are means $+/-$ one standard deviation. A Chi squared analysis with Yates correction was used in Table 4.

\section{Results}

The thirty patients studied included twelve females and eighteen males. Patient mean age was 29.4 years (range 14-55). The symptoms and signs at presentation are listed in Table 1. Nineteen patients presented with neurologic manifestations. Ten patients presented with coma, three with seizures, three with coma and seizures, and three with reduced visual acuity. Of the thirteen who were comatose on arrival at the hospital, seven

Table 1: Symptoms and Signs at Presentation to Hospital in Patients with Methanol Poisoning

\begin{tabular}{lc}
\hline \hline Signs and Symptoms & Number of Patients $(\mathbf{n}=\mathbf{3 0})$ \\
\hline Nausea & 8 \\
Abdominal Pain & 5 \\
Headache & 1 \\
Decreased Visual Acuity & 3 \\
Retinal edema & 3 \\
Unreactive pupils & 8 \\
Stupor & 3 \\
Coma & 13 \\
Seizures & 6 \\
\hline
\end{tabular}

died. The three patients with reduced visual acuity at presentation were all left with visual sequelae. Four of the six patients presenting with seizures died, one was left with a persistent seizure disorder, and only one of the six patients made a full recovery.

The mean blood $\mathrm{pH}$ was significantly lower in the patients with neurologic manifestations on admission (Table 2). Although the methanol levels tended to be higher in patients with neurologic symptoms and signs than in those without neurologic manifestations, there was considerable overlap between the two groups. Most of the patients with initial neurologic manifestations arrived at hospital more than eight hours after methanol ingestion. However the time from ingestion to presentation was not significantly different in the patients with neurologic manifestations as compared to those without (Table 4).

\section{Neurologic Sequelae}

Fifteen of the thirty patients went on to develop long term neurologic sequelae or died. These included four patients with ocular toxicity defined as a decrease in visual acuity to less than $20 / 100$. Three other patients developed neurologic sequelae secondary to central nervous system damage. These patients have been reported previously. ${ }^{27}$ One, a 55 year old female, remained in a chronic vegetative state. Her CT scan showed diffuse white and grey matter destruction. Another patient, a 31-year-old male, developed a transverse myelopathy at $\mathrm{T} 4$. The third patient, a 30-year-old male, showed persistent personality and cognitive changes. Eight patients died. The mean blood $\mathrm{pH}$ was significantly decreased in this group of fifteen patients with poor neurologic outcome or death as compared to the mean blood $\mathrm{pH}$ in the fifteen patients with good outcome (Table 3). Clinical outcome was also improved if treatment was initiated within eight hours of methanol ingestion. None of the five patients in whom treatment was started within eight hours of ingestion developed neurologic sequelae or died (Table 4). Methanol levels were not different in patients with neurologic sequelae or death as compared to patients with good outcome.

\section{Discussion}

Methanol poisoning has long been associated with a high mortality rate. The mortality rate of $26 \%$ in our patient series is comparable to previous reports. ${ }^{1,3,5}$ Survivors of methanol poisoning may be left with serious long term neurologic sequelae.

Table 2: Methanol Levels and $\mathrm{pH}$ at Presentation as Related to the Presence of Major Neurologic Symptoms and Signs at Presentation

\begin{tabular}{lccc}
\hline \hline Variable & $\begin{array}{c}\text { Major Neurologic } \\
\text { Symptoms and Signs } \\
(\mathbf{n}-19)\end{array}$ & $\begin{array}{c}\text { No Major Neurologic } \\
\text { Symptoms and Signs } \\
(\mathbf{n}-11)\end{array}$ \\
\hline $\begin{array}{l}\text { MEAN pH } \\
+/-1 \text { S.D. } \\
\text { (range) }\end{array}$ & $\begin{array}{c}6.96+1-10.28 \\
(6.46-7.42)\end{array}$ & $\begin{array}{c}7.24+/-10.07 \\
(7.16-7.35)\end{array}$ \\
$\begin{array}{l}\text { MEAN METHANOL } \\
+/-1 \text { S.D. }\end{array}$ & $93.8+/-90$ & $34+/-26$ & $\mathrm{NS}$ \\
in mmol/L & $(4-213)$ & $(1-315)$ & \\
\hline (range) & & &
\end{tabular}

$*_{\mathrm{p}}<0.05$

NS Not significant 
These are being recognized with increasing frequency as more patients survive because of intensive care unit treatment. Visual sequelae with optic disc pallor, retinal edema and blindness have been reported. ${ }^{16,17}$ Sharpe et al ${ }^{19}$ have described optic nerve demyelination with relative preservation of axons in patients dying of methanol poisoning. White matter destruction elsewhere in the central nervous system has also been seen. 24 Putamenal hemorrhage on CT scan has been reported after methanol poisoning 20 and was noted on CT scan in two of our patients with neurologic sequelae. ${ }^{27}$ Autopsy studies on patients with methanol poisoning have shown changes ranging from mild cerebral edema to large basal ganglia hemorrhages. 1,2,24,25 Basal ganglia hemorrhage is a common finding in patients dying of methanol ingestion. 2,25 These reported changes in central nervous system white and grey matter are sufficient to explain most of the various neurologic syndromes seen after methanol poisoning. These syndromes include parkinsonism, $21,23,24,26$ pseudobulbar palsy, 3,5 cognitive defects with myelopathy, 24,27 and frontal release signs. 5,24

Martin-Amat et al ${ }^{18}$ and McMartin et $\mathrm{al}^{9}$ have shown that formate is the toxic agent responsible for the ocular damage, and formate is believed to be responsible for the non-ocular neurologic sequelae as well, although this has not yet been clearly established.

Which factors determine whether patients will present with neurologic symptoms and signs? In our patient group, patients with neurologic symptoms and signs on presentation had lower blood $\mathrm{pH}$ levels, and tended to have higher methanol levels.

Table 3: Methanol Levels and pH at Presentation as Related to Outcome in 30 Patients with Methanol Poisoning

\begin{tabular}{lcc}
\hline Variable & $\begin{array}{c}\text { Major Sequelae } \\
\text { or Death } \\
(\mathbf{n}=\mathbf{1 5})\end{array}$ & $\begin{array}{c}\text { Survival with } \\
\text { No Major Sequelae } \\
(\mathbf{n}=\mathbf{1 5})\end{array}$ \\
\hline $\begin{array}{l}\text { MEAN pH } \\
+/-1 \text { S.D. } \\
\text { (range) }\end{array}$ & $\begin{array}{l}6.94+/-0.28 \\
(6.46-7.42)\end{array}$ & $\begin{array}{l}7.17+/-0.19 \\
(6.67-7.35)\end{array}$ \\
$\begin{array}{l}\text { MEAN METHANOL } \\
+/-1 \text { S.D. } \\
\text { in mmol/L }\end{array}$ & $74.9+/-63$ & $67.8+/-0.96 \mathrm{NS}$ \\
(range) & $(5-315)$ & $(1-84)$ \\
\hline
\end{tabular}

*p $<0.05$

NS Not significant
Schwartz et al, 6 in a study of 44 patients, showed that a low $\mathrm{pH}$ correlated with the presence of confusion and coma at presentation, but made no comment about the final outcome in these patients. They also showed that methanol levels tended to be higher in patients with severe neurologic signs and symptoms. In our study, those patients presenting with coma, seizures, or decreased visual acuity also tended to have a poor outcome.

The factors related to outcome and long term sequelae have been studied in more detail. Bennett et al ${ }^{1}$ found that if the plasma $\mathrm{CO}_{2}$ was less than $20 \mathrm{mEq}$ the mortality rate was $19 \%$, but if the $\mathrm{CO}_{2}$ was less than $10 \mathrm{mEq}$ the mortality rate was $50 \%$. However, others have reviewed the literature and found a trend but not a significant difference in the bicarbonate concentration in those patients with major sequelae (death and visual changes) versus those with no long term complications. 28 Pappas and Silverman ${ }^{15}$ in a study of twelve patients found that the mean $\mathrm{pH}$ was lower in those patients that died. In our study, the $\mathrm{pH}$ was significantly lower in those patients with neurologic sequelae or death.

Methanol levels have been used as a criterion for aggressive treatment of methanol intoxication with hemodialysis, but have never been shown to correlate with outcome in terms of mortality or visual sequelae. ${ }^{10,15,28}$ There was no correlation between methanol levels and outcome in our study. This is likely because it is not the methanol but the conversion to formate that is responsible for the metabolic acidosis and structural damage to the central nervous system. In view of this, it is not surprising that a delay in treatment has an adverse affect on outcome. Gonda et al ${ }^{28}$ concluded that the interval from ingestion to treatment was important in determining outcome in his nine patients. Our present study also demonstrated that the interval from ingestion to treatment is important. Patients who could be treated promptly did significantly better than those in whom treatment was delayed. Fifty percent of our patients developed neurologic sequelae or death, and this poor outcome appeared to be related to a low $\mathrm{pH}$ at presentation and a delay in the initiation of treatment. Methanol levels did not correlate with outcome. Thus, it must be stressed that methanol levels should not be used as the sole criterion for aggressive treatment of methanol poisoning. Patients with a delay in presentation, especially if systemic acidosis has occurred are at significant risk for the development of long term neurologic sequelae. Early treatment remains the best way of avoiding serious neurologic complications and death in patients with methanol poisoning.

Table 4: Time to Presentation Related to Outcome and Symptoms and Signs at Presentation in 30 Patients with Methanol Poisoning

\begin{tabular}{|c|c|c|c|c|}
\hline Time & $\begin{array}{l}\text { Neurological } \\
\text { Sequelae } \\
\text { or Death } \\
(\mathbf{n}=15)\end{array}$ & $\begin{array}{c}\text { Survivors } \\
\text { with } \\
\text { No Sequelae } \\
(\mathbf{n}=15)\end{array}$ & $\begin{array}{c}\text { Neuro } \\
\text { Manifestations } \\
\text { at Presentation } \\
(\mathbf{n}=\mathbf{1 9})\end{array}$ & $\begin{array}{c}\text { No Neuro } \\
\text { Manifestations } \\
\text { at Presentation } \\
(n=11) \\
\end{array}$ \\
\hline $\begin{array}{l}\text { Less than } \\
8 \text { hours }\end{array}$ & 0 & $5 *$ & 2 & 3 \\
\hline $\begin{array}{l}\text { More than } \\
8 \text { hours }\end{array}$ & 15 & 6 & 15 & 6 \\
\hline Unknown & 0 & 4 & 2 & 2 \\
\hline
\end{tabular}

* $p<0.05$ for the No Sequelae group vs. the Neurological Sequelae or death group for less than 8 hours compared to greater than 8 hours. 


\section{REFERENCES}

1. Bennett IL, Cary FH, Mitchell GL, et al. Acute methyl alcohol poisoning: a review based on experiences in an outbreak of 323 cases. Medicine 1953; 32: 431-463.

2. Erlanson P, Fritz H, Hagstam KE, et al. Severe methanol intoxication. Acta Med Scand 1965; 177: 393-407.

3. Naraqi S, Dethlefs R, Slobodniuk R, et al. An outbreak of acute methyl alcohol intoxication. Aust NZ J Med 1979; 9: 65-68.

4. Roe $O$. Methanol poisoning: its clinical course, pathogenesis and treatment. Acta Med Scand 1946; 126: (Suppl 2).

5. Scrimgeour EM. Outbreak of methanol isopropanol poisoning in New Britain, Papau New Guinea. Med J Aust 1980; 2: 36-38.

6. Schwartz RD, Millman RP, Billi JE, et al. Epidemic methanol poisoning: clinical and biochemical analysis of a recent episode. Medicine 1981; 60: 373-82.

7. Becker CE. Methanol poisoning. J Emerg Med 1983; 1: 51-58.

8. Fulop M. Methanol intoxication. Lancet 1982; 338.

9. McMartin KE, Ambre JJ, Tephly TR. Methanol poisoning in human subjects. Am J Med 1980; 68: 414-418.

10. Osterloh J, Pond S, Grady S, et al. Serum formate concentrations in methanol intoxication as a criterion for hemodialysis. Ann Intern Med 1986; 104: 200-203.

11. Jacobsen D, Ovreb S, Sejersted O. Toxicokinetics of formate during hemodialysis. Acta Med Scand 1983; 214: 409-412.

12. Ekins BR, Rollins DE, Duffy DP, et al. Standardized treatment of severe methanol poisoning with ethanol and hemodialysis. West J Med 1985; 142: 337-340.

13. Keyvan-Larijarni H, Tannenberg AM. Methanol intoxication. Arch Intern Med 1974; 134: 293-296.

14. McCoy HG, Cipolle RJ, Ehlers SM, et al. Severe methanol poisoning. Am J Med 1979; 67: 804-807.

15. Pappas SC, Silverman $M$. Treatment of methanol poisoning with ethanol and hemodialysis. Can Med Assoc J 1982; 126: 13911394.
16. Dethlefs R, Naraqi S. Ocular manifestations and complications of acute methyl alcohol intoxication. Med J Aust 1978; 2: 483-485.

17. Ingemansson SO. Clinical observations on ten cases of methanol poisoning with particular reference to ocular manifestations. Acta Ophthalmol 1984; 62: 15-24.

18. Martin-Amat G, McMartin KE, Hayreh SS, et al. Methanol poisoning: ocular toxicity produced by formate. Toxicol Appl Pharmacol 1978; 45: 201-208.

19. Sharp JA, Hostovsky M, Bilbao JM, et al. Methanol optic neuropathy: a histopathological study. Neurology 1982; 32: 1093-1100.

20. Aquilonius SM, Askmark H, Enoksson P, et al. Computerised tomography in severe methanol intoxication. Brit Med J 1978; 929-930.

21. Guggenheim MA, Couch JR, Weinberg W. Motor dysfunction as a permanent complication of methanol ingestion. Arch Neurol 1971; 24: 550-554.

22. Henzi H. Chronic methanol poisoning with the clinical and pathologic anatomical features of multiple sclerosis. Med Hypotheses 1984; 13: 63-75.

23. Ley CO, Gali FG. Parkinsonian syndrome after methanol intoxication. Eur Neurol 1983; 22: 405-409.

24. McLean DR, Jacobs H, Mielke BW. Methanol poisoning: a clinical and pathological study. Ann Neurol 1980; 8: 161-167.

25. Orthner H. Methylalkoholvergiftung mit besonders Schweren Hirnveraenderungen. Virchows Archives 1953; 323: 443-464.

26. Riegal H, Wolff F. Schwere Neurologische Ausfaelle als folge einer Methylalkohol Vergiftung. Fortschr Neurol Psychiatr 1966; 34: 346-351.

27. Anderson TJ, Shuaib A, Becker WJ. Neurological sequelae of methanol poisoning. Can Med Assoc J 1987; 136: 1177-1179.

28. Gonda A, Gault H, Churchill D, et al. Hemodialysis for Methanol Intoxication. Am J Med 1978; 64: 749-758. 